\title{
Saccharin Extraction And Analysis Of Drug And Food Samples By Derivative Ultraviolet (UV) Spectrophotometry
}

\section{Ekstraksi Dan Analisis Sakarin Dalam Sampel Obat Dan Makanan Secara Spektrofotometri Ultraviolet (UV) Derivativ}

\author{
Sarwendah Ratnawati Hermanto ${ }^{a^{*}}$, Roto, Agus Kuncaka ${ }^{b}$ \\ ${ }^{a}$ Politeknik Negeri Ketapang, Jl. Rangga Sentap Dalong Ketapang, Kalbar 78813 \\ ${ }^{b}$ Universitas Gadjah Mada, Jalan Sekip Utara Bulaksumur, Yogyakarta, telp. (0274)545188 \\ *Corresponding author: sarwendah.ratnawati.hr@gmail.com
}

\begin{abstract}
Saccharin extraction and analysis of drug and food samples was investegated by spectrophotometry ultraviolet $(u v)$ derivative method were studied. The saccharin extraction was carried out using solvent of ethanol/chloroform (2:8 v/v). The limit of detection (LOD) and limit of quantification (LOQ) of the proposed method were $0.50 \mathrm{ppm}$ and $1.82 \mathrm{ppm}$ for the second order and $0.47 \mathrm{ppm}$ and $1.58 \mathrm{ppm}$ for the fourth, while for the zero order were 2,75 ppm and 8,55 ppm. The calibration curve was linear in the concentration range from 20-100 ppm $\left(R^{2}=0.996\right.$ for the second order and $R^{2}=0.997$ for the fourth). The percent recovery of saccharin was in the range 95.20-104.40\% for the second order and 97.20-102.40\% for the fourth. The range of saccharin concentration $(w / w)$ in drugs, candies and toothpaste for the fourth derivative were $1.39 \pm 0.02 \mathrm{mg} / \mathrm{kg}$ until $7.15 \pm 0.05 \mathrm{mg} / \mathrm{kg}, 0.21 \pm 0.01 \mathrm{mg} / \mathrm{kg}$ until $2.09 \pm 0.01$ $\mathrm{mg} / \mathrm{kg}$, and $0.15 \pm 0.03 \mathrm{mg} / \mathrm{kg}$ until $0.63 \pm 0.04 \mathrm{mg} / \mathrm{kg}$, respectively.
\end{abstract}

Keywords : analysis, derivative UV spectrophotometry, extraction, saccharin

\begin{abstract}
Abstrak
Ekstraksi dan analisis sakarin dalam sampel makanan dan obat secara spektrofotometri ultraviolet derivatif telah dilakukan. Ekstraksi dilakukan menggunakan pelarut kloroform-etanol (2:8 $\mathrm{v} / \mathrm{v})$. Puncak maksimum derivatif berturut-turut untuk orde kedua dan keempat terdapat pada panjang gelombang $280 \mathrm{~nm}$ dan $278 \mathrm{~nm}$. Batas deteksi (LOD) dan batas kuantifikasi (LOQ) sebesar 0,39-0,50 ppm dan 1,32-1,82 ppm, serta 0,42-0,47 ppm dan 1,41-1,48 ppm. Kurva standar linear pada rentang konsentrasi $20-100 \mathrm{ppm}$ diperoleh $\mathrm{R}^{2}=0,996$ dan $\mathrm{R}^{2}=0,997$. Persentase perolehan kembali analisis sakarin sebesar 94,60-109,40\% dan 97,20-110,20\%. Konsentrasi sakarin dalam obat, permen dan pasta gigi masing-masing sebesar 0,00-7,15 mg/kg, 0,4 $\pm 0,06$ $\mathrm{mg} / \mathrm{kg}$ sampai $17 \pm 1 \mathrm{mg} / \mathrm{kg}$, dan $0,1 \pm 0,05 \mathrm{mg} / \mathrm{kg}$ sampai $19 \pm 0,9 \mathrm{mg} / \mathrm{kg}$.
\end{abstract}

Kata kunci : analisis, ekstraksi, sakarin, spektrofotometri UV derivative

\section{Pendahuluan}

Belakangan ini, produk bebas gula (sugar free) menjadi sangat popular karena mengandung kalori yang rendah, sehingga industri menggunakan berbagai macam pemanis buatan yang dianggap rendah kalori. Pemanis merupakan salah satu bahan tambahan pangan yang rasanya mirip dengan gula dan sering disebut sebagai pengganti gula (Chattopadhyay dkk., 2014). Konsumen dan industri makanan, obat serta 
kosmetik tertarik untuk mengganti pemanis alami karena pemanis buatan dianggap mampu menjaga citarasa manis tanpa perlu khawatir terhadap kerusakan gigi meskipun keamanan penggunaan pemanis buatan ini masih menjadi kontroversi (Whitehouse dkk., 2008).

Sakarin adalah salah satu pemanis buatan non-kalori yang sudah banyak digunakan dalam berbagai jenis makanan sejak 60 tahun lalu dengan tingkat kemanisan sekitar 300 kali sukrosa (Hussein dkk., 1976). Sakarin berupa serbuk atau hablur putih, tidak berbau atau berbau aromatik lemah, bereaksi asam terhadap lakmus, agak sukar larut dalam air, dalam kloroform dan dalam eter, larut dalam air mendidih, sukar larut dalam etanol, mudah larut dalam larutan ammonia encer, dalam larutan natrium hidroksida dan natrium karbonat dengan pembentukan karbondioksida. Kombinasi penggunaan sakarin dengan pemanis buatan rendah kalori lainnya bersifat sinergis (Anonim, 1995).

Berdasarkan Food and Drug Administration (FDA) penggunaan pemanis buatan dikatakan aman apabila sesuai dengan batas Acceptable Daily Intake (ADI) meskipun sampai saat ini dilaporkan masih menyebabkan gangguan kesehatan dan metabolisme (Chattopadhyay dkk., 2014). Dalam Peraturan Menteri Kesehatan Republik Indonesia No.208/Menkes/Per/IV/1985 disebukan bahwa batas penggunaan sakarin yang sesuai dengan ADI adalah 02,5 $\mathrm{mg} / \mathrm{kg}$ berat badan per hari, sedangkan dalam SNI Nomor 01-69932004 dan berdasar Join Expert Committee on Food Additive (JECFA) tahun 1993 serta dalam The Scientific Committee on Food of the European Commission (SCFEC) tahun 1995 batas ADI meningkat menjadi $5 \mathrm{mg} / \mathrm{kg}$ berat badan (Cantarelli dkk., 2008). Menurut Kroger dkk., (2006) sakarin dapat menyebabkan kanker kandung kemih hanya pada tikus jantan dan tumor yang dapat terjadi akibat akumulasi sakarin yang dikonsumsi dalam dosis tinggi dan dalam waktu yang lama.

Sakarin biasa digunakan bersamaan dengan zat aditif lainnya dalam sampel makanan dan obat. Isolasi sakarin dari sampel makanan dan minuman dapat dilakukan dengan cara ekstraksi. Berbagai metode ekstraksi telah dilakukan sejak beberapa tahun lalu, antara lain dengan menggunakan karbon tetraklorida $\left(\mathrm{CCl}_{4}\right)$ dalam sampel minuman ringan (Hussein dkk., 1976), dengan Nile Blue (NB) dalam sampel pemanis dan minuman ringan 
(Cordoba dkk., 1984), dengan menggunakan dietil eter (AOAC, 2000), dan dengan menggunakan etanol dalam sampel tablet pemanis (Weinert dkk., 2004).

Metode analisis yang dapat mendeteksi kadar sakarin yang terdapat pada suatu produk baik makanan, minuman, kosmetik serta obat-obatan sangat diperlukan dalam rangka meningkatkan keamanan penggunaaan. Metode analisis sakarin dalam sampel minuman maupun makanan dapat dilakukan dengan menggunakan beberapa metode yaitu metode titrimetri, spektrofotometri ultraviolet dan tampak, HPLC, gravimetri, turbidimetri, kromatografi, potensio-metri dan polarografi. Akan tetapi beberapa metode tersebut membutuhkan banyak waktu, hanya dapat digunakan untuk sampel dengan kadar yang relatif besar dan tingginya biaya analisis serta keterbatasan dalam ketersediaan alat tersebut menyebabkan metode ini sulit digunakan untuk analisis rutin pada laboratorium yang memiliki keter-batasan peralatan.

Sakarin memiliki gugus kromofor yang terdapat pada rentang panjang gelombang ultraviolet. Pengembangan metode pektrofotometri ultraviolet pun dilakukan dengan harapan diperolehnya hasil analisis yang lebih sensitif dan akurat, salah satunya dengan optimalisasi derivatif (Turak dan Ozgur, 2014). Metode spektroskopi derivatif sangat cocok untuk analisis pita absorbsi yang overlapping atau terlalu landai (Owen, 1995).

Alpdogan dkk. (2002) menggunakan turunan kedua dan ketiga dalam analisis penentuan kafein pada minuman ringan (cola, kopi dan teh). Linieritas berada pada rentang konsentrasi 2-10 $\mu \mathrm{g} / \mathrm{mL}$ dan limit deteksi 1,5-2 $\mu \mathrm{g} / \mathrm{mL}$. Vidotti dkk. (2005) melakukan analisis terhadap campuran zat warna (Amaranth, Brilliant Blue, Sunset Yellow dan Tartrazine) dengan spektrofotometri UV derivatif pertama dan diperoleh persen recovery sebesar 96$101 \%$.

Berdasarkan fakta tersebut maka dilakukan pengembangan terhadap metode spektrofotometri ultraviolet untuk penentuan kadar sakarin pada sampel makanan dan obat. Optimasi dilakukan untuk memperoleh kondisi optimum yang akan digunakan dalam penelitian. Sebelum penentuan kadar sakarin dalam sampel maka terlebih dahulu dilakukan validasi untuk memastikan bahwa metode yang digunakan telah memenuhi parameter validasi (linearitas, ketepatan, ketelitian, batas deteksi (Limit of Detection, LOD), batas 
kuantifikasi (Limit of Quantification, LOQ) dan sensitivitas).

Penelitian ini dilakukan dengan tujuan untuk [1] mengetahui nilai persen perolehan kembali (\%) recovery dari hasil ekstraksi menggunakan etanol-kloroform secara spektrofoto-metri ultraviolet derivatif, [2] mengetahui nilai batas deteksi (LOD), batas kuantifikasi (LOQ) dan sensitivitas dari analisis sakarin secara spektrofotometri ultraviolet derivatif, [3] mengetahui nilai batas zat-zat yang menyebabkan interferensi dalam analisis sakarin secara spektrofotometri ultraviolet derivatif, [4] memperoleh metode spektrofotometri ultraviolet derivatif yang valid sesuai parameter validasi pada penentuan kadar sakarin dalam sampel obat dan makanan.

\section{Metode Penelitian}

\section{Bahan}

Sakarin $\left(\mathrm{C}_{7} \mathrm{H}_{5} \mathrm{NO}_{3} \mathrm{~S}\right)$ (Analytical grade, Aldrich), larutan natrium hidroksida $(\mathrm{NaOH})$, larutan asam klorida pekat $(\mathrm{HCl})$, kloroform $\left(\mathrm{CHCl}_{3}\right)$, etanol $96 \%\left(\mathrm{C}_{2} \mathrm{H}_{6} \mathrm{O}\right)$, asam sitrat $\left(\mathrm{C}_{6} \mathrm{H}_{8} \mathrm{O}_{7}\right)$, natrium benzoat $\left(\mathrm{C}_{6} \mathrm{H}_{5} \mathrm{COONa}\right)$, kalium sorbat $\quad\left(\mathrm{C}_{5} \mathrm{H}_{7} \mathrm{COOK}\right), \quad$ sukrosa $\left(\mathrm{C}_{12} \mathrm{H}_{22} \mathrm{O}_{11}\right)$, dan siklamat $\left(\mathrm{C}_{6} \mathrm{H}_{12} \mathrm{NNaO}_{3} \mathrm{~S}\right) \quad$ (Analytical grade, Merck). Aspartam $\left(\mathrm{C}_{14} \mathrm{H}_{18} \mathrm{~N}_{2} \mathrm{O}_{5}\right)$ (Tech- nical grade, CV. Chemix Pratama) serta akuabides (Laboratorium PAU UGM). Sampel yang digunakan pada penelitian ini adalah obat, permen dan pasta gigi yang beredar di pasaran.

\section{Peralatan}

Peralatan yang digunakan dalam penelitian ini antara lain timbangan analitik (Mettler AE 100), $\mathrm{pH}$ meter HM-30R. Satu set alat rotary evaporator (Buchii) untuk menguapkan pelarut setelah diekstraksi. Spektrofotometer UV-Vis (GBC Scientific Equipment, Cintra 2020) digunakan untuk analisis.

Hipotesis akan dibuktikan dengan melakukan langkah kerja penelitian sebagai berikut. Langkah pertama adalah optimasi dan validasi analisis sakarin untuk zero order (tanpa derivatisasi). Optimasi meliputi pemilihan panjang gelombang maksimum dan pengukuran beberapa parameter validasi seperti linieritas, ketepatan, ketelitian, batas deteksi (Limit of Detection, LOD), batas kuantifikasi (Limit of Quantification, LOQ) dan sensitivitas).

Langkah kedua adalah optimasi ekstraksi sakarin dari fasa air ke dalam fasa organik. Optimasi meliputi pemilihan jenis solven (pelarut), penentuan rasio volume pelarut, volume pelarut, 
lama waktu penggojogan, lama waktu pendiaman, $\mathrm{pH}$, dan uji interferensi.

Langkah ketiga yaitu optimasi spektra derivatif. Optimasi meliputi pembuatan spektra derivatif kesatu sampai derivat keempat dan pengukuran beberapa parameter validasi seperti linieritas, ketepatan, ketelitian, batas deteksi (Limit of Detection, LOD), batas kuantifikasi (Limit of Quantification, LOQ) dan sensitivitas). Dari hasil langkah ketiga ini, maka akan ditentukan orde terbaik yang memenuhi beberapa parameter validasi untuk kemudian digunakan dalam analisis sampel.

\section{Pembahasan}

Gambar 1 menunjukkan bahwa larutan standar sakarin memiliki $\lambda$ maksimum $270 \mathrm{~nm}$. Larutan sakarin tidak memberikan serapan pada panjang gelombang di atas $300 \mathrm{~nm}$. Panjang gelombang maksimum yang diperoleh ini sesuai dengan berbagai penelitian dalam analisis sakarin menggunakan metode spektrofotometri UV yaitu $265 \mathrm{~nm}$ (Hussein dkk., 1976), 270 nm (Fix dan Pollack, 1980) dan 268 nm (Soarez dan Martins, 2002). Gambar 1 memperlihatkan spektra yang landai, dengan puncak yang tidak terlalu tajam.

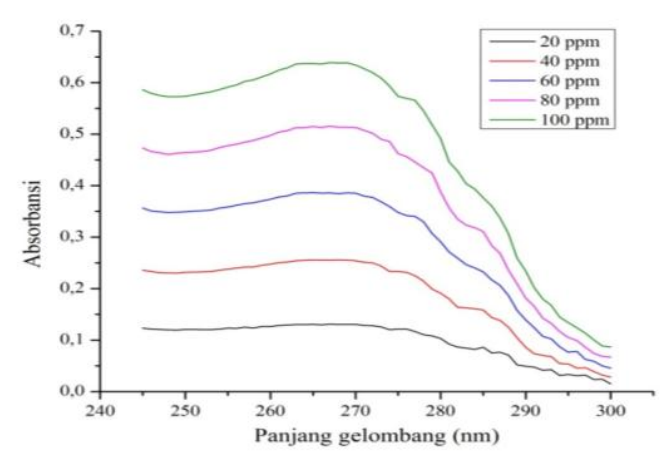

Gambar 1. Spektra UV derivatif orde ke-nol larutan standar sakarin pada konsentrasi 20, 40, 60, 80 dan 100 ppm

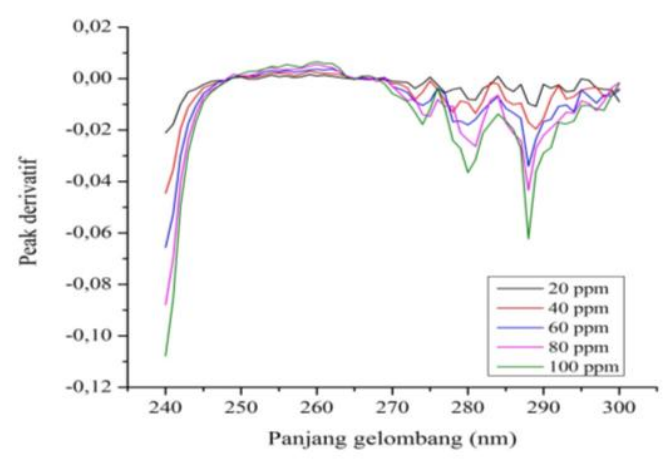

Gambar 2. Spektra UV derivatif orde ke-1 larutan standar sakarin pada konsentrasi 20, 40, 60, 80 dan 100 ppm

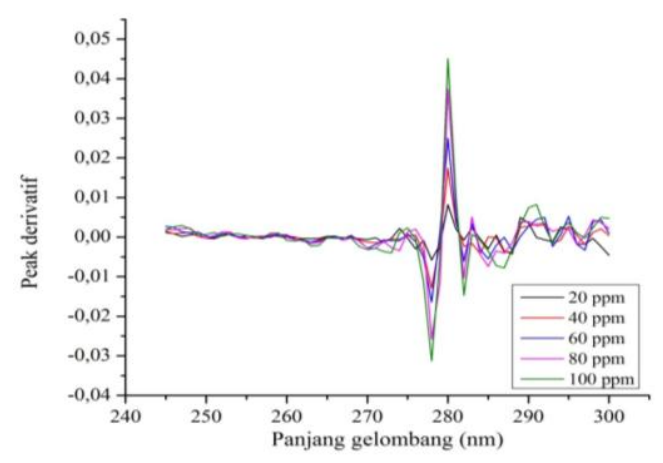

Gambar 3. Spektra UV derivatif orde ke-2 larutan standar sakarin pada konsentrasi 20, 40, 60, 80 dan 100 ppm 


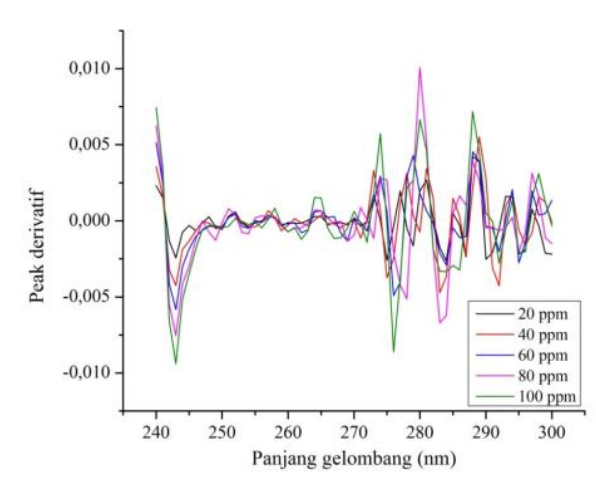

Gambar 4. Spektra UV derivatif orde ke-3 larutan standar sakarin pada konsentrasi 20, 40, 60, 80 dan 100 ppm

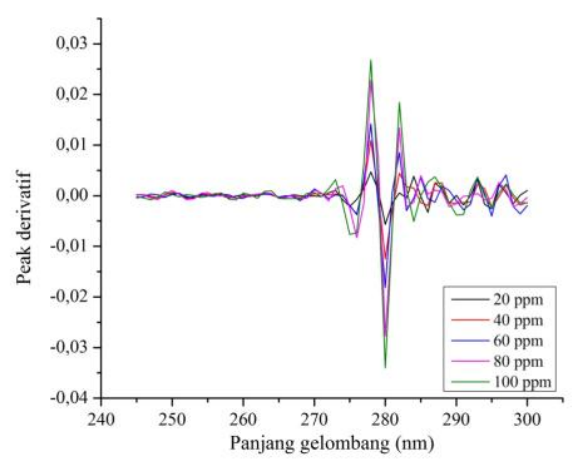

Gambar 5. Spektra UV derivatif orde ke-4 larutan standar sakarin pada konsentrasi 20, 40, 60, 80 dan 100 ppm

Hasil optimasi ekstraksi sakarin dari fasa air ke fasa organik menunjukkan bahwa sakarin dapat diekstraksi menggunakan $100 \mathrm{~mL}$ pelarut etanolkloroform $(2: 8 \mathrm{v} / \mathrm{v})$ pada suasana asam (pH 3-5) selama 2 menit dengan waktu pendiaman 5 menit sebelum diuapkan dengan rotavapor untuk diambil residunya. Optimasi derivatif standar sakarin dilakukan untuk memperoleh kurva linier yang lebih sensitif, presisi dan akurat untuk menentukan konsentrasi sakarin dalam sampel.
Dalam penelitian ini, dibuat empat spektra derivatif sakarin pada rentang konsentrasi 20-100 ppm pada panjang gelombang 240-300 nm. Spektra sakarin dari orde 1 sampai orde 4 disajikan dalam Gambar 2 sampai dengan Gambar 5 dan kemudian akan dibuat kurva kalibrasinya untuk spektra yang memperlihatkan keteraturan bentuk peak seiring bertambahnya konsentrasi.

Berdasarkan keempat spektra tersebut dapat dilihat bahwa terjadi pergeseran panjang gelombang terbentuknya spektra jika dibandingkan dengan spektra pada orde ke-nol dan pada spektra derivatif, spektra yang terbentuk lebih tajam dibandingkan dengan orde ke-nol. Berdasarkan Gambar 2 sampai dengan Gambar 5 maka dapat dilihat bahwa pada spektra derivatif orde ke-2 dan orde ke-4 mempunyai keteraturan kenaikan peak yang baik.

Berdasarkan Tabel 1 dapat dilihat bahwa orde kenol, kedua dan keempat memiliki nilai koefisien korelasi yang hampir mendekati satu yaitu 0,999 untuk orde ke-nol, 0,996 untuk orde kedua dan 0,997 untuk orde keempat, sehingga hal ini menunjukkan bahwa orde kedua dan keempat mempunyai linieritas yang lebih baik dibandingkan orde kesatu dan 
ketiga. Hasil penelitian terdahulu menyebutkan linieritas pada derivatif orde kedua memiliki nilai koefisien korelasi $\mathrm{R}^{2}=0,9974$ dengan persamaan regresi $\mathrm{y}=0,369 \mathrm{x}+0,0002$ (Tedjo dan Apriliany, 2010). Ozgur dan Koyuncu (2000) juga menyebutkan bahwa orde kedua linier dengan nilai $\mathrm{R}^{2}=0,9997$ dan persamaan $\mathrm{y}=0,07762 \mathrm{x}+0,0068$. Analisis kafein dalam teh pada derivatif orde ketiga telah dilakukan dan diperoleh nilai
$\mathrm{R}^{2}=0,9999$ dengan persamaan $\mathrm{y}=0,071+0,01$ (Alpdogan dkk., 2002). Turak dan Ozgur (2014) menyebutkan linieritas analisis acesulfam-K pada derivatif orde kesatu dengan nilai $\mathrm{R}^{2}=0,9998$ dan persamaan regresi $y=1,01 x+0,071$ serta untuk aspartame pada derivatif orde ketiga dengan nilai $\mathrm{R}^{2}=0,9995$ dan persamaan regresi $y=0,00002 x-0,000003$.

Tabel 1. Perbandingan linieritas derivatif order $0,1,2,3$ dan 4

\begin{tabular}{cccccc}
\hline Paramater & Orde ke-nol & Orde ke-1 & Orde ke-2 & Orde ke-3 & Orde ke-4 \\
\hline $\begin{array}{c}\text { Persamaan } \\
\text { regresi }\end{array}$ & $\mathrm{y}=0,006 \mathrm{x}+0,001$ & $\mathrm{y}=0,003 \mathrm{x}-0,005$ & $\mathrm{y}=0,007 \mathrm{x}-0,018$ & $\mathrm{y}=0,001 \mathrm{x}-0,000$ & $\mathrm{y}=0,006 \mathrm{x}-0,013$ \\
$\begin{array}{c}\text { Koefisien } \\
\text { korelasi }\end{array}$ & 0,999 & 0,962 & 0,996 & 0,989 & 0,997 \\
\hline
\end{tabular}

Tabel 2. Perbandingan nilai LOD, LOQ dan \%RSD larutan standar sakarin pada order 0, 2 dan 4

\begin{tabular}{cccc}
\hline Paramater & Orde ke-nol & Orde ke-2 & Orde ke-4 \\
\hline LOD & $2,75 \mathrm{ppm}$ & $0,5 \mathrm{ppm}$ & $0,47 \mathrm{ppm}$ \\
LOQ & $8,55 \mathrm{ppm}$ & $1,82 \mathrm{ppm}$ & $1,58 \mathrm{ppm}$ \\
\%RSD & $0,073-0,781$ & $0,482-1,901$ & $0,474-0,853$ \\
\hline
\end{tabular}

Tabel 3. Persen perolehan kembali ketiga sampel (obat, permen dan pasta gigi) pada derivatif orde ke-2

\begin{tabular}{cccccc}
\hline \multirow{2}{*}{ Sampel } & \multirow{2}{*}{ Penambahan $(\mathrm{mg} / \mathrm{L})$} & \multicolumn{2}{c}{ Terukur $(\mathrm{mg} / \mathrm{L})$} & \multicolumn{2}{c}{ Recovery $(\%)$} \\
\cline { 2 - 5 } & & ZP & PP & ZP & PP \\
\hline \multirow{2}{*}{ Obat } & 5 & 4,85 & 4,87 & 97,00 & 97,40 \\
& 10 & 9,46 & 10,04 & 94,60 & 100,40 \\
& 20 & 19,85 & 20,12 & 99,25 & 100,60 \\
Permen & 5 & 4,84 & 4,88 & 96,80 & 97,60 \\
& 10 & 9,96 & 9,52 & 99,60 & 95,20 \\
& 20 & 19,54 & 19,61 & 97,70 & 98,05 \\
& 5 & 6,35 & 6,47 & 97,00 & 99,40 \\
& 10 & 11,46 & 11,94 & 99,60 & 104,40 \\
& 20 & 21,55 & 21,42 & 100,25 & 99,60 \\
\hline
\end{tabular}


Tabel 4. Persen perolehan kembali ketiga sampel (obat, permen dan pasta gigi) pada derivatif orde ke-4

\begin{tabular}{cccccc}
\hline \multirow{2}{*}{ Sampel } & \multirow{2}{*}{ Penambahan $(\mathrm{mg} / \mathrm{L})$} & \multicolumn{2}{c}{ Terukur $(\mathrm{mg} / \mathrm{L})$} & \multicolumn{2}{c}{ Recovery $(\%)$} \\
\cline { 3 - 6 } & & ZP & PP & ZP & PP \\
\hline \multirow{2}{*}{ Obat } & 5 & 5,05 & 5,12 & 101 & 102,4 \\
& 10 & 9,89 & 9,72 & 98,9 & 97,2 \\
& 20 & 19,87 & 19,73 & 99,35 & 98,65 \\
Permen & 5 & 5,04 & 4,97 & 100,8 & 99,4 \\
& 10 & 10,16 & 10,28 & 101,6 & 102,8 \\
& 20 & 20,04 & 19,87 & 100,2 & 99,35 \\
Pasta gigi & 5 & 6,65 & 6,44 & 103 & 98,8 \\
& 10 & 11,61 & 11,44 & 101,1 & 99,4 \\
& 20 & 21,86 & 21,57 & 101,8 & 100,35 \\
\hline
\end{tabular}

Metode evaluasi kuantitatif dari spektrum derivatif yang digunakan adalah peak to peak. Presisi atau ketelitian ditentukan dengan mengukur absorbansi dari tiga larutan standar dengan konsentrasi yang berbeda. Pada pengukuran presisi, dilakukan perhitungan rerata (mean), deviasi standar dan persen deviasi standar $(\%$ RSD). Pengukuran dilakukan sebanyak tiga kali pengulangan pada hari yang sama (intraday) dan tiga kali pengulangan pada hari yang berbeda (interday). Dalam penelitian ini, penentuan presisi dilakukan untuk orde ke-nol, orde ke-2, dan orde ke-4.

Berdasarkan Tabel 2 dapat dilihat bahwa derivatisasi spektra dapat menurunkan nilai LOD dan LOQ. Pada orde ke-nol jumlah terkecil analit yang dapat terdeteksi kemudian memberikan respon signifikan dibandingkan larutan blanko adalah 2,75 ppm dan kuantitas terkecil analit yang dapat memenuhi kriteria akurasi (ketepatan) adalah 8,55 ppm, sedangkan pada orde kedua dan keempat nilai LOD dan LOQ lebih kecil dibandingkan orde ke-nol. Persen RSD yang dihasilkan dari ketiga orde tersebut selama 3 hari berturut-turut adalah kurang dari 2\%. Hal ini menunjukkan bahwa metode yang digunakan sudah memenuhi parameter validasi yaitu presisi.

Hasil penelitian terdahulu menyebutkan nilai LOD analisis sakarin dalam minuman ringan dengan metode spektrofotometri UV-Vis sebesar $1,55 \times 10^{-5}$ M (Weinert dkk., 2004). Derivatif orde pertama dan ketiga digunakan dalam penentuan benzophenone yang mempunyai nilai LOD dan LOQ berturut-turut sebesar 0,04-0,11 ppm dan $0,13 \quad-\quad 0,34 \quad$ ppm 
(Walash dkk., 2011). Analisis sakarin dalam tablet pemanis dengan metode spektrofotometri UV memiliki nilai \%RSD 0,53-0,72\% (Soarez dan Martins, 1995). Penentuan asam askorbat pada orde kedua dan ketiga dalam sayuran juga telah dilakukan dan diperoleh nilai \%RSD sebesar 0,89 2,99\% (Aydogmus dan Cetin, 2002). Turak dan Ozgur (2014) menyebutkan analisis acesulfam-K pada derivatif orde kesatu diperoleh nilai \%RSD sebesar $0,17-0,85 \%$ dan $0,53-0,81 \%$ pada derivatif orde ketiga.

Pengukuran akurasi (ketepatan) dilakukan dengan menghitung persen perolehan kembali (\% recovery). Sampel yang mengandung sakarin (lima sampel pasta gigi, lima sampel obat, dan tujuh sampel permen). Hasil persen perolehan kembali dapat dilihat pada Tabel 3 dan Tabel 4.

Tabel 3 menunjukkan hasil persen perolehan kembali pada sampel yang diukur pada derivatif orde ke-2 berkisar antara $94,60 \%$ sampai $100,25 \%$ untuk zero peak dan untuk peak to peak berkisar antara 95,20\% sampai 104,40\%. Pada Tabel 4 menunjukkan hasil persen perolehan kembali pada sampel yang diukur pada derivatif orde ke-4 berkisar antara 98,05\% sampai
$101,80 \%$ untuk zero peak dan untuk peak to peak berkisar antara 97,20\% sampai $102,80 \%$. Hal ini menunjukkan bahwa metode analisis sakarin secara spektrofotometri UV derivatif memenuhi salah satu parameter validasi akurasi (ketelitian).

Hasil penelitian terdahulu menyebutkan nilai \% perolehan kembali analisis sakarin dengan metode spektrofotometri UV sebesar 83 - 113\% (Hussein dkk., 1976), dan sebesar 95,51 104,76\% (Soarez dan Martins, 1995). Analisis sakarin dalam tablet pemanis dengan metode spektrofotometri UV memiliki nilai \% recovery 99,2 104,3\% (Weinert dkk., 2002). Analisis sakarin dengan metode capillary electrophoresis juga telah dilakukan dan diperoleh nilai \%recovery sebesar 95,8 $-110,0 \%$ (Cantarelli dkk., 2008).

Pada uraian sebelumnya telah diketahui bahwa metode analisis sakarin secara spektrofotometri UV derivatif dapat memberikan hasil yang baik dan memenuhi parameter validasi yaitu linearitas, ketelitian, batas deteksi dan batas kuantifikasi, ketepatan serta sensitivitas. Dengan demikian, metode analisis sakarin secara spektrofotometri UV derivatif dapat digunakan dalam sampel obat, permen dan pasta gigi. 
Sampel obat yang digunakan dalam penelitian ini adalah suplemen makanan dan multivitamin anak-anak, sampel permen terdiri dari empat permen gulagula dan tiga permen karet. Sampel pasta gigi yang digunakan pada penelitian ini adalah pasta gigi anak-anak.

\section{Kesimpulan}

Berdasarkan hasil penelitian dan pembahasan yang telah dikemukakan, maka dapat diperoleh beberapa kesimpulan sebagai berikut : (1) Persen perolehan kembali (recovery) sakarin pada ketiga sampel untuk orde kedua sebesar 94,60\%-104,40\% sedangkan untuk orde keempat sebesar 97,20\%$102,40 \%$. (2) LOD dan LOQ berturutturut sebesar 0,39-0,5 ppm dan 1,321,82 ppm untuk orde kedua, sedangkan untuk orde keempat sebesar 0,42-0,47 ppm dan 1,41-1,48 ppm. (3) Penentuan konsentrasi sakarin yang ada pada setiap sampel diulang sebanyak tiga kali dan dihitung pada orde keempat. Konsentrasi sakarin yang terdapat dalam sampel obat sebesar 1,39 $\pm 0,02 \mathrm{mg} / \mathrm{kg}$ sampai $7,15 \pm 0,05 \mathrm{mg} / \mathrm{kg}$, pada sampel permen sebesar $0,21 \pm 0,01 \mathrm{mg} / \mathrm{kg}$ sampai $2,09 \pm 0,01 \mathrm{mg} / \mathrm{kg}$ dan pada sampel pasta gigi sebesar $0,15 \pm 0,03 \mathrm{mg} / \mathrm{kg}$ sampai $0,63 \pm 0,04 \mathrm{mg} / \mathrm{kg}$.

\section{Ucapan Terima Kasih}

Ucapan terimakasih penulis sampaikan kepada Direktorat Pendidikan Tinggi (Dikti) atas beasiswa penelitian yang diberikan pada Program BPPDN 2013 dan semua pihak yang membantu dalam penelitian ini.

\section{Pustaka}

Anonim, 1995, Direktorat Jenderal Pengawasan Obat dan Makanan Farmakope Indonesia Edisi ke 4. Jakarta, Departemen Kesehatan.

Alpdogan, G, Karabina, K, and Sungur, S, 2002, Derivative Spectrophotometric Determination of Caffeine in Some Beverages, Turk. J. Chem., 26, 295-302.

AOAC, Official Method 934.04, Saccharin in Non Alcoholic Beverages, $17^{\text {th }}$ ed, Association of Official Analytical Chemists, Arlington, 2000, p 47-48.

Aydogmus, Z, and Cetin, S.M., 2002, Determination of Ascorbic Acid in Vegetables by Derivative Spectrophotometry, Turk. J. Chem., 26, 697-704.

Cantarelli, M.A., Pellerano, R.G., Marchevsky, E.J., and Camina, J.M., 2008, Simultaneous Determination of Saccharin and Aspartame in Commercial Noncaloric Sweeteners Using the PLS-2 Multivariate Calibration and Validation by Capillary Electrophoresis, J. Agric. Food. Chem., 56, 9345-9349. 
Chattopadhyay, S, Raychaudhuri, U, and Chakraborty, R, 2014, Artificial Sweeteners, J. Food. Sci. Technol., 51(4), 611-621.

Cordoba, M.H., Garcia, I.L., and Pedreno, C.S., 1985, Spectrophotometric Determination of Saccharin in Different Materials by A Solvent Extraction Method Using Nile Blue As Reagent, Talanta., 4, 325-327.

Fix, G.L., and Pollack, J.D., 1980, Determination of Saccharin in Watts Nickel Plating Solutions by First Derivative Ultraviolet Spectrometry, Anal. Chem., 52, 1589-1592.

Hussein, M.M., Jacin, H, and Rodriguez, F.B., 1976, Quantitative Determination of Saccharin in Food Products by Ultraviolet Spectrophotometry, J. Agric. Food. Chem., 24(1), 36-40.

Kroger, M, Meister, K, and Kava, R., 2006, Low-calorie Sweeteners and Other Sugar Substitutes: A Review of The Safety Issues, Compr. Rev. Food. Sci., 5, 3547.

Owen, T, 1996, Fundamental of $U V$ Visible Spectroscopy, Waldbronn: Hewlett-Packard.

Ozgur, M.U., and Koyuncu, I, 2002, The Simultaneous Determination of Quinoline Yellow (E104) and Sunset Yellow (E-110) in Syrups and Tablets by Second Derivative Spectrophotometry, Turk. J. Chem., 26(2002), 501508.

Soarez, C.D.V., and Martins J.L.S., 1995, Derivative Ultraviolet
Spectrophotometric Determination of Saccharin in Artificial Sweeteners, Braz. J. Pharm. Sci., 120, 193-195.

Soarez, C.D.V., and Martins J.L.S., 2002, Saccharin Analysis in Pharmaceutical and Cosmetic Preparation by Derivative Ultraviolet Spectrophotometry, Braz. J. Pharm. Sci., 38, 471-478.

Turak, F, and Ozgur, M.U., 2014, Validated Spectrophotometric Methods for Simultaneous Determination of Food Colorants and Sweeteners, J. Chem., 2013, 1-9.

Tedjo, A, dan Apriliany, T.R., 2010, Penetapan Kadar Cilastatin dan Imipenem dalam Sediaan Injeksi Kering secara Spektrofotometri Derivatif, Farmasains., 1, 2, 5661.

Vidotti, E.C., Cancino, J.C., Oliveira, C.C, and Rollemberg, M.D.C.C., 2005, Simultaneous Determination of Food Dyes by First Derivative Spectrophotometry with Sorption onto Polyurethane Foam, Anal. Sci., 21(2), 149153.

Walash, M.I., Rizk, M.S., Sheribah, Z.A., and Salim, M.M., 2011, Derivative Spectrophotometric Analysis of Benzophenone (as an impurity) in Phenytoin, Chem. Central. J., 5(85), 1-10.

Weinert, P.L., Pezza, H.R., Oliveira, J.E., and Pezza, L., 2004, A Simplified Spectrophotometric Method for Routine Analysis of Saccharin in Commercial Noncaloric Sweeteners, J. Agric. Food. Chem., 52, 7788-7792. 
Whitehouse, C.R., Boullata, J, and McCauley, L.A., 2008, The Potential Toxicity of Artificial Sweeteners. AAOHN Journal., 56(6), 251-259.

Saccharin Extraction And Analysis Of Drug And Food Samples By Derivative Ultraviolet (UV) Spectrophotometry 